\title{
Higher Education: Free Tuition Vs. Quotas Vs. Targeted Vouchers
}

\author{
- Eduardo de Carvalho Andrade*
}

\begin{abstract}
Resumo
Este trabalho compara, do ponto de vista teórico, três sistemas universitários alternativos: o atual adotado pelo Brasil, no qual os alunos das universidades públicas, que são praticamente gratuitas, são escolhidos através de um processo seletivo; um sistema de quotas nas universidades públicas para beneficiar estudantes de baixa renda; e um sistema de vouchers direcionados para estudantes de baixa renda que podem ser utilizados nas universidades privadas ou públicas. A comparação destes três sistemas indica que o último é o mais eficiente, pois gera: (i) maior qualidade da mão de obra; (ii) alocação mais eficiente dos recursos; e (iii) maior mobilidade social.
\end{abstract}

Palavras-Chave

financiamento educacional, vouchers educacionais, eficiência, capital humano

\begin{abstract}
This paper compares theoretically three alternative university systems: the current one adopted in Brazil, in which students who perform better in the entering exam obtain the right to attend the public university without paying the full tuition; a system of affirmative action quotas in public universities, to benefit low income students; and a targeted vouchers system that can be used either to pay private or public university tuiton. The comparison indicates that the last system leads to: (i) a higher quality of the labor force; (ii) a more efficient allocation of resources; and (iii) a greater social mobility.
\end{abstract}

\section{Keywords}

educational finance, educational vouchers, efficiency, human capital

\section{JEL Classification}

$\mathrm{HO}, \mathrm{H} 41, \mathrm{I22}, \mathrm{I} 28$

\footnotetext{
* Professor of Economics at Insper. Corresponding address: Rua Quatá 300/4th floor, Vila Olímpia, São Paulo, Brazil, 04546-042. Email address: eduardo.andrade@insper.org.br. (Recebido em janeiro de 2008. Aceito para publicação em setembro de 2009).
} 


\section{Introduction}

The Brazilian higher education sector has two important characteristics. First, there is a mix of private and public universities coexisting. The fraction of students enrolled in private universities was equal to $74.6 \%$ in $2006 .{ }^{1}$ Second, the government heavily subsidizes higher education by financing fully (or almost fully) public universities' tuitions. For instance, an individual whose income per capita is equal to the country's income per capita and whose child studies in a public university receives a transfer from the government aproximatelly equal to $51 \%$ of his income. In contrast, the same number for Argentina, South Korea and United States are, respectively, equal to $16.2 \%, 5 \%$ and $26 \% .^{2}$

There are two main justifications to use government money to finance higher education. The first one is to promote equality of opportunity by correcting the lack of capital markets to finance education. The second one is to produce positive externalities. It is not clear that the current university system is the most efficient to accomplish these goals.

On the one hand, the system is clearly regressive and does not promote equality of opportunity. It is financed through tax revenues by all individuals in the economy. The mechanisms to select students to attend the public universities is a very strict one in which only students who pass a competitive entrance exam are accepted. The system implies a transfer from the rich to the poor. Its beneficiaries are in general students coming from high income families. The reasons are obvious. Rich families' offspring receive a higher quality pre-university education which allows them either to finish high school or to perform better in the competitive entrance exams for the public universities. They choose the public option over the private one either because the public universities are better or because it is not worth " paying twice" for a better education (through tax and tuition in private universities). In Brazil, 76\% of all public expenditures in higher education are directed to the top 20\% richest families in the population. Only 3\% are directed to the $60 \%$ poorest families.

On the other hand, the presence of externalities may not justify the current system. First, it is not necessarily optimum to subsidize every student at the same rate. Mostly important, given the financial difficulties of the governments and the potential alternative uses of the money, it is desirable to use more efficiently the public resources.

Given the inadequacy of the current system, it is worth analyzing other options. This paper's objective is to compare theoretically three systems. The first one mi-

1 See Andrade et al (2009).

2 These numbers were extracted from Veloso and Ferreira (2006). 
mics the current system and it is called free tuition regime. It is assumed that the public universities are tuition free. The students who obtain the highest scores in the entrance exams can attend the public universities. The second one is the targeted vouchers system. Under this scheme, public tuitions are not free. Low income students receive vouchers that can be used either to pay private or public tuition. The others have to sponsor fully their higher education. ${ }^{3}$ The third regime is quotas. Under this option, public universities are tuition-free. However, it is guaranteed the admission of a certain number of students from the target groups (coming from low income families) in public universities. These beneficiaries replace students from non-target groups who would have the right to attend the tuition-free public universities in the free tuition regime. Such a system has been adopted in some Brazilian public universities and the government has plans to expand it to all federal universities.

The analysis suggests that the targeted vouchers system is the best among the three examined. It produces the highest quality of the labor force, the greatest social mobility and the most efficient allocation of total resources (private and public) in higher education. Its advantage is related to the fact that it directs public resources only to those individuals who really need financial support to attend an university.

There are some papers related to this one. It adapts a framework developed by Caucutt and Kumar (2003), which analyses the effects of increasing higher education subsidies in the US on inequality, welfare and efficiency. They do not examine the effects of quotas and targeted vouchers. Chen and West (2000) studies the median voter choice between the universal and selective vouchers but in primary and secondary education. Andrade (2004) compares quotas with the free-tuition regime. The main novelty of this paper is to analyze the targeted voucher regime, which turns out to be the most efficient one.

The paper is organized as follows. Section 2 lays out the structure of the model. The following section describes the competitive equilibrium in each system. Section 4 compares the efficiency of the three regimes (tuition free, quotas and targeted vouchers). Section 5 discusses how robust the results are to some changes in the structure of the model. The final section concludes.

3 To my knowledge, there is no voucher system in the higher education sector. Pro-poor voucher plans operate in some countries (e.g., Colombia, Guatemala, the United States), but only in lower levels of education, not in universities. Chile is the only example of a nationwide schools voucher system, in the line proposed by Friedman (1962), not selective. For different funding mechanisms for higher education in the world, see Albrecht and Ziderman (1992). 


\section{Model}

The model employs a two-period economy. There are two types of families, which differ by the parent's level of human capital. At time $t=0$, parent has either a high or a low level of human capital. Each parent works, receives wages, decides whether to send his child to university, consumes, and dies. At time $t=1$, the child becomes a worker with high or low level of human capital, depending on the educational decision of his parent, receives a wage, and consumes. The measure of each generation (and the number of workers in each period) is constant and is normalized to one. Let $n_{h, t}$ and $n_{l, t}$ be the fraction of individuals, respectively, with high and low levels of human capital at time $t$. Note that $n_{h, 0}=n_{h, 0}^{*}$ and $n_{l, 0}=n_{l, 0}^{*}$ are exogenously given, and $n_{h, 0}^{*}+n_{l, 0}^{*}=1$.

As I do not model the schooling decision, it is assumed that all children have a school degree and are able to attend university. However, they differ in their ability to perform well at university and become an individual with a high level of human capital. A child with ability $a$ who attends a private university becomes an individual with high or low level of human capital, respectively, with probability $\pi_{p r}(a)$ and $\left(1-\pi_{p r}(a)\right)$. In the case of attending a public university, the equivalent probability can differ and is denoted by $\pi_{p u}(a)$. If the quality of the public university is greater than the private, then $\pi_{p u}(a)>\pi_{p r}(a), \forall a$. The inequality reverses if the opposite holds, that is, if the private university has a higher quality. This feature of the model limits the heterogeneity to two levels of human capital, and therefore to two income levels, which simplifies the analysis. If a child does not attend university, he has the lower level of human capital with probability equal to one. Let $F($.$) be the distribution function for ability on the support [0,1]$, and $f($.$) be the$ corresponding density function. As in Caucutt and Kumar (op. cit.), the distribution is identical across types and within families of the same type, and all ability draws are independent of each other. ${ }^{4}$

Assumption 1: $a \in 0,1], 0 \leq \pi_{j}(a) \leq 1, \pi_{j}^{\prime}(a)>0, \pi_{j}^{\prime \prime}(a)<0, \forall a$, and $\pi_{j}(0)=0$, $j=p r, p u$.

The parent whose child has ability $a$ may have three options: sending the child to attend the public or the private university, or alternatively, letting the child remain solely with a school degree. His problem can be written in the following way:

4 In this paper, the term ability includes cognitive and non-cognitive abilities. See Cunha et al. (2006) and Cunha and Heckman (2009) for a lenght discussion on the impact of cognitive and non-cognitive abilities and parent's education on the student performance, as well as early and late investments in education affecting many individuals' behaviors and income. 


$$
\begin{aligned}
& \max _{p u, p r, s}\left\{u\left((1-\tau) w_{i, 0}-E_{p u}+V\right)+\beta \pi_{p u}(a) u\left(w_{h, 1}\right)+\right. \\
& \left.+\left(1-\pi_{p u}(a)\right) u\left(w_{l, 1}\right)\right] ; \\
& u\left((1-\tau) w_{i, 0}-E_{p r}+V\right)+\beta\left[\pi_{p r}(a) u\left(w_{h, 1}\right)+\left(1-\pi_{p r}(a)\right) u\left(w_{l, 1}\right)\right] ; \\
& \left.u\left((1-\tau) w_{i, 0}\right)+\beta u\left(w_{l, 1}\right)\right\}, i=h, l .
\end{aligned}
$$

where $\tau$ is the income tax, $\beta$ is the discount factor, $w_{i, t}$ is the wage of individual with $i$ level of human capital at time $t, E_{p u}$ is the public university tuition, $E_{p r}$ is the private university tuition, $V$ is the voucher that can be used either in private or public university, and the utility function $u$ has the usual properties. The university tuition can be seen as the cost per student in terms of units of consumption. The first term within the parenthesis in the above problem indicates the public university option, which may be available to the family. ${ }^{5}$ At $t=0$, the family receives its wage net of taxes, may have to pay the public university tuition and may receive vouchers to pay the child's education. It consumes and sends its child to a public university. At $t=1$, the child becomes either a worker with high or low level of human capital, based on the quality of the public university, and earns his wage. The second term indicates the private university option, which is available to all families who have enough resources to pay the tuition. 6,7 The difference with respect to the first option is that the probability of the child becoming an individual with high level of human capital is now based on the quality of the private university. The last term within the parenthesis is the option of not sending the child to university at all. The family pays taxes and the child becomes a worker with low level of human capital.

The family's problem above differs slightly depending which regime is in place: free tuition in public universities $(f)$, quotas $(q)$ and targeted vouchers $(v)$. Under the free tuition regime, there are no vouchers and the public university tuition is free. Hence, $E_{p u}$ and $V$ are equal to zero. Moreover, there is a fixed number $s$ of places $(s<<1)$ in public universities. As the number of applicants is greater than $s$, it is necessary to have some form of rationing.

In Brazil, this rationing is made through exams that all applicants must take. The accepted students are those who achieve the highest scores. In order to mimic this

5 See discussion below about which families have the public university option.

6 As it is assumed that there is no capital market to finance investments in education, the private university option is not available to those families that do not receive vouchers and whose wage net of taxes is lower than the private university tuition.

7 The price (cost) of private education is assumed to be fixed and equal to $E_{p r}$. Thus, the number of students that are enrolled in the private universities is endogenously determined. Implicitly, it is assumed, for simplicity, that there is perfect competition in the private market for education with competitors having the same cost structure. 
current system of students' selection to the public universities, it is assumed that the students who achieve the highest scores are the ones with greater abilities. Hence, the $s$ individuals with greater ability obtain the right to attend the public university, independently of their family's income background. ${ }^{8}$ Formally, the ability ranges of the individuals from high and low income families who acquire the right to attend public university under regime $f$ are, respectively, equal to $\left[a_{p u, h}^{f}, 1\right]$ and $\left[a_{p u, l}^{f}, 1\right]$, such that: $s=n_{h, 0}^{*} \int_{a_{p u, h}^{f}}^{1} f(a) d a+n_{l, 0}^{*} \int_{a_{p u, l}^{f}}^{1} f(a) d a .{ }^{9}$ Only those families whose children obtain the right to attend the public university have the three options mentioned in problem (1) under the free tuition regime. The others would have only the last two options: either to send their children to private university or let them remain solely with a school degree.

Under the quota regime, as in the free tuition regime, there are no vouchers and the public university tuition is free $\left(E_{p u}=V=0\right)$. The introduction of quotas into the system has the effect of changing the individuals who have the right to attend public universities and, thus, the ability range of the individual who attend public universities. This change occurs formally in the following way. The $c$ individuals with the lowest ability levels compared to other individuals of their background, who had the right to attend the public university and whose parents have a high level of human capital, lose their right to attend public universities. In their place, the $c$ individuals with the highest ability levels among individuals of their backgrounds, who did not have the right to attend a public university and whose parents have a low level of human capital, acquire that right. Therefore, the new ability range of the individuals who attend public universities under regime $q$ are the following. It becomes equal to $\left[a_{p u, h}^{q}, 1\right]$ and $\left[a_{p u, l}^{q}, 1\right]$, respectively, for those individuals whose parents have high and low level of human capital. The abilities $a_{p u, h}^{q}$ and $a_{p u, l}^{q}$ are obtained, respectively, from the following equations: $c=n_{h, 0}^{*} \int_{a_{p u, l}^{p}}^{a_{p u, h}^{q}} f(a) d a=n_{l, 0}^{*} \int_{a_{p u, l}^{q}}^{a_{p u, l}^{f}} f(a) d a .{ }^{10}$ This set-up indicates that, when quotas are introduced, some high income families lose their right to send their children to public university, which are transferred to some low income families. In this way, this feature of the model tries to mimic the types of quotas that has been introduced in Brazil, which are intended to benefit either black or public schools students who in general are from low income families. ${ }^{11}$ Hence, with quotas, there is a new

8 With assumption 2 below, the s individuals with the highest abilities actually decide to attend the public universities under the free tuition regime.

9 Note that $a_{p u, i}^{f}=a_{p u, h}^{f}$.

10 Note that $a_{p u, h}^{q}>a_{p u, l}^{q}$

11 For more details, see Andrade (2004). 
set of families whose children have the right to attend the public university. They are the ones now with the three options in problem (1). The other families can choose from only the other two alternatives: private universities or no university.

Under the targeted voucher system, students have to pay tuition to attend public universities. In addition, students from low income families may receive vouchers that can be used to pay full tuition either in private or public university. To simplify the analysis, I assume that, when tuition are charged in public universities, private and public tuitions are equal $\left(E_{p r}=E_{p u}=E\right)$. For those families who receive vouchers, $V$ is positive and equal to E. For the others, $V$ is equal to zero and $E$ is positive. It is important to define which low income families are eligible to receive the vouchers. They are the ones with the highest ability levels among those families who do not send their children to attend university without the financial aid from the government. It is important to emphasize that the targeted voucher system is different from the other two because it directs public resources only to those families who really need financial support to provide an university degree to their children. ${ }^{12} \mathrm{I}$ define the ability range of the individuals who receive vouchers as $\left[a_{\mathrm{inf}}^{v}, a_{\mathrm{sup}}^{v}\right]$. Total number of vouchers distributed are equal to $s$. Hence, $s=n_{l, 0}^{*} \int_{a_{\text {inf }}^{v}}^{a_{s u p}^{v}} f(a) d a$. The number of places available in the public universities are still the same and equal to $s$. If public universities face excess demand, I assume that the individuals with the highest abilities have the right to attend them. However, the places available in the public universities may not be filled under the targeted voucher system as they are not free anymore and their quality may be lower than the private ones.

Recall that, independently of which regime is in place, each family has to pay an income tax $(\tau)$ at $t=0$. Income tax are the sole source of revenues to the government. Under the free tuition or quota regimes, public university students do not pay tuition which is financed by the government. Assuming that the cost per student is equal to $\mathrm{E}$, government expenditures are equal to $s E$. Under the voucher system, $s$ vouchers are distributed and each one has a face value equal to $E$. This amount is sufficient to pay $s$ full tuitions either in the private or public university. Total government expenditures are also equal to $s E$. As a result, the model is constructed in a way that total expenditures by the government are the same in all regimes, which

12 The targeted voucher system used in the model is certainly not the most efficient one. In particular, it could have been proposed one in which targeted families with lower ability children receive more generous vouchers. As a result, more children would attend university as it is clearly not necessary to pay the full tuition to " convince" the targeted families with the relatively brighest children to choose the university option. Nonetheless, for simplicity, I use a targeted voucher system in which all recipients receive vouchers with the same face value. For a further discussion on different voucher systems and its impacts, see Neal (2002) and Ladd (2002). 
makes the three regimes comparable. Government's budget constraint, which has to be in equilibrium, is the following:

$$
\tau\left(n_{h, 0}^{*} w_{h, 0}+n_{l, 0}^{*} w_{l, 0}\right)=s E .
$$

There is a single non-storable good in the economy produced by firms operating in a competititve market. There is no physical capital in the economy. The only inputs in the production process are the two types of labor, with high and low levels of human capital. The single technology, which has constant returns to scale, produces goods that can be consumed or invested in education and is as follows:

$$
Y_{t}=A N_{h, t}^{\alpha}\left(N_{h, t}+N_{l, t}\right)^{1-\alpha}
$$

where $A>0 ; 0<\alpha<1 ; N_{h, t}$ and $N_{l, t}$ are, respectively, the number of individuals with high and low levels of human capital employed in the production process at time $t$. The idea behind this production function is the following. Workers with high level of human capital provide two distinct productive services, physical effort (" brawn") and mental effort (" brains")" . Workers with low level of human capital is capable of providing only the former. In other words, in order to be able to execute more sophisticated tasks the individual must acquire a higher level of human capital. ${ }^{13}$ It is easy to check that the greater is the fraction of individuals with high level of human capital, the greater is total production. Moreover, as each type of labor is paid its marginal product, $w_{h, t}$ is always greater than $w_{l, t}$.

\section{Competitive Equilibrium}

This section discusses the competitive equilibrium of the model under the three different regimes: free $(f)$, quotas $(q)$ and targeted vouchers $(v)$. I restrict the analysis in any regime to equilibria that incorporate two features. First, families always use the option offered by the government if available to them, either to use their right to attend the public university (in the free tuition or quota regimes) or the vouchers in the best available university. Second, there is also private investment in education. In other words, the expected skill premium, resulted from the sole public expenditures in education in any regime, is large enough to give incentives for at least some families to invest their own resources in private education.

13 Andrade (1998) uses the same production function, which is a simplified version from the one employed by Stokey (1996). 
The reason for adopting these two features in the model is that they are characteristics of the system in the countries mentioned in the introduction. In general, individuals opt to attend public universities because they are (almost) free in order to avoid paying twice for education (through tax and tuition in private universities). It may occur even if a private university has a higher quality. ${ }^{14}$ Moreover, there is a mix of private and public universities coexisting. These characteristics are likely to remain if the two alternative regimes discussed here, the quotas and targeted voucher regimes, are introduced.

Let $w_{i, 1}^{\prime}$ be the wage of worker type $i(i=h, l)$ at time $t=1$ if the $s$ individuals with the right to attend public university under the quota regime choose the public option and there is no private investment in education. Recall that the lowest ability level of all individuals who acquire the right to attend public university under the quota regime is equal to $a_{p u, l}^{q}$. The following assumption guarantees that the differences in quality between both types of universities are not large enough to justify the investment $E$ in private education under the quota regime when the public option is available:

$$
\begin{aligned}
& \text { Assumption } \left.2:^{15}(1-\tau) w_{h, 0}>E \text { and for any } a, a \in a_{p u, l}^{q}, 1\right] \text {, } \\
& \qquad u\left((1-\tau) w_{h, 0}\right)-u\left((1-\tau) w_{h, 0}-E\right)>\beta\left(\pi_{p r}(a)-\pi_{p u}(a)\right)\left(u\left(w_{h, 1}^{\prime}\right)-u\left(w_{l, 1}^{\prime}\right)\right) .
\end{aligned}
$$

It is interesting to mention what this assumption implies to the equilibrium under the free tuition regime. As mentioned in the previous section, quota changes the individuals who have the right to attend public universities, reducing their average quality. Hence, without any private investment in education, the skill premium is certainly lower with quotas in comparison with the free tuition regime. As a result, if it does not justify the investment in private education in the quota regime when the public option is available, it must also hold in the free tuition regime.

In the vouchers regime, obviously, the recipient families always opt to send their children to the university with higher quality. The others alternatives (either no university or the one with lower quality) become redundant.

14 Using the notation of the model, even if $\pi_{p r}(a)>\pi_{p u}(a), \forall a$.

15 Obviously, if it is not worth to high income families to choose the private option when the public one is available, the same holds for low income families. Moreover, if low income families do not have enough resources to pay for private education (that is, if $(1-\tau) w_{0.1}<E$ ), they do not invest in private education. Finally, note that having chosen the public option without any private investment in education, the families certainly continue choosing the public option when there are also private investments in education in the economy as the skill premium is lower. 
Thus, as pointed out above, the type of equilibrium that is the focus of this paper is the one in which the families always use the option offered by the government. Formally, the following holds in the equilibria examined. Under the free tuition regime, the ability ranges of the indivuals from high and income families who actually attend the public universities are, respectively, equal to $\left[a_{p u, h}^{f}, 1\right]$ and $\left[a_{p u, l}^{f}, 1\right]$. Under the quota regime, the corresponding ability ranges are $\left[a_{p u, h}^{q}, 1\right]$ and $\left[a_{p u, l}^{q}, 1\right]$. Under the targeted voucher regime, the ability range of the individuals from low income families who use the vouchers is $\left[a_{\mathrm{inf}}^{v}, a_{\mathrm{sup}}^{v}\right]$.

The following assumption is sufficient to restrict the analysis to equilibria in which there is private investment in education under the free tuition and quotas regimes:

Assumption $3:^{16} \beta \pi_{p r}\left(a_{p u, l}^{q}\right)\left[u\left(w_{h, 1}^{\prime}\right)-u\left(w_{l, 1}^{\prime}\right)\right]>u\left((1-\tau) w_{i, 0}\right)-u\left((1-\tau) w_{i, 0}-E\right)$, for $i=h$ and if $(1-\tau) w_{l, 0}>E$ for $i=l$.

Some of high income families whose children do not have the right to attend public university are made better off by investing in private education instead of not sending their children to university. The same is valid to low income families as long as their net wage of tax is greater than the university tuition $\left((1-\tau) w_{l, 0}>E\right)$. Otherwise, there is no private investment in education made by low income families as there is no capital market to finance education in the model.

Let $w_{i, 1}^{\prime \prime}$ be the wage to worker type $i(i=h, l)$ at time $t=1$ if the $s$ individuals who receive vouchers attend the university with the highest quality. Recall that $a_{\mathrm{inf}}^{v}$ is the lowest ability level of all individuals who receive vouchers. The following is a sufficient assumption to guarantee that there is private investment in education under the targeted voucher regime.

\section{Assumption $4::^{17}$}

$$
\begin{aligned}
& \beta \pi_{p r}\left(a_{\mathrm{inf}}^{v}\right)\left[u\left(w_{h, 1}^{\prime \prime}\right)-u\left(w_{l, 1}^{\prime \prime}\right)\right] \\
& >u\left((1-\tau) w_{i, 0}\right)-u\left((1-\tau) w_{i, 0}-E\right),
\end{aligned}
$$

for $i=h$ and if $(1-\tau) w_{l, 0}>E$ for $i=l$.

16 Note that this assumption guarantees that there is private investment in education under the quota regime. As the skill premium is higher when there is no private investment in education under the free tuition regime, it follows that there is also private investment in education under the free tuition regime.

17 The economic intuition behind this condition is equivalent to the one in assumption 3 . 
I now turn to the definition and the proof of existence and uniqueness of the equilibrium under regime $j(j=f, q, v)$ :

Definition 1: Given $s, c, E_{p u}, E_{p r}, E, V$ and $n_{h, 0}^{*}$, a competitive equilibrium under regime $j$ is characterized by $n_{i, 1}^{j}, w_{i, 0}^{j}, w_{i, 1}^{j}, a_{p u, i}^{j}$ and $a_{p r, i}^{j}(i=h, l)$, and $a_{\text {inf }}^{v}$ and $a_{\text {sup }}^{v}$ under regime $v$, such that: (i) given wages, firms maximize profits; (ii) the labor market clears, that is, $N_{h, t}=n_{h, t}^{j}$ and $N_{l, t}=n_{l, t}^{j}(t=0,1)$; (iii) $a_{p u, h}^{f}=a_{p u, l}^{f}$ is obtained from the following equation for $s, s=n_{h, 0}^{*} \int_{a_{p u, h}^{f}}^{1} f(a) d a+n_{l, 0}^{*} \int_{a_{p u, l}^{f}}^{1} f(a) d a$; (iv) $a_{p u, l}^{q}$ and $a_{p u, i}^{q}$ are obtained from the following equations for $c, c=n_{h, 0}^{*} \int_{a_{p u, l}^{f}}^{a_{p u, h}^{q}} f(a) d a=n_{l, 0}^{*} \int_{a_{p u, l}^{q}}^{a_{p u, l}^{f}} f(a) d a$; (v) given wages, $s, c, E_{p u}, E_{p r}, E$ and $V, a_{p u, i}^{j}$ and $a_{p r, i}^{j}$ solve the university decision problem of family $i$ in () under regime $j$ such that individuals with ability ranges $\left[a_{p u, i}^{j}, 1\right]$ and $\left[a_{p r, i}^{j}, a_{p u, i}^{j}\right]$ attend, respectively, public and private universities.(v) $a_{\text {sup }}^{v}$ and $a_{\text {inf }}^{v}$ are obtained, respectively, from the following equations, $a_{\text {sup }}^{v}=a_{p r, l}^{v}$ and $s=n_{l, 0}^{*} \int_{a_{\text {inf }}^{v}}^{a_{\text {sup }}^{v}} f(a) d a$; (vi) under regime $v$, individuals from low income families with ability range $\left[a_{\text {inf }}^{v}, a_{p r, l}^{v}\right]$ attend the type of university with higher quality; (vii) the government's budget constraint is in equilibrium; and (viii) the law of motion for the variables $n_{h, t}^{k}(k=f, q)$ and $n_{h, t}^{v}$, which are, respectively, given by:

$$
\begin{aligned}
& n_{h, 1}^{k}=n_{h, 0}^{*}\left[\int_{a_{p u, h}^{k}}^{1} \pi_{p u}(a) f(a) d a+\int_{a_{p r, h}^{k}}^{a_{p u, h}^{k}} \pi_{p r}(a) f(a) d a\right]+ \\
& +n_{l, 0}^{*}\left[\int_{a_{p u, l}^{k}}^{1} \pi_{p u}(a) f(a) d a+\int_{a_{p r, l}^{k}}^{a_{p u, l}^{k}} \pi_{p r}(a) f(a) d a\right]
\end{aligned}
$$

and

$$
\begin{aligned}
& n_{h, 1}^{v}=n_{h, 0}^{*}\left[\int_{a_{p u, h}^{v}}^{1} \pi_{p u}(a) f(a) d a+\int_{a_{p r, h}^{v}}^{a_{p u, h}^{v}} \pi_{p r}(a) f(a) d a\right]+ \\
& n_{l, 0}^{*}\left[\int_{a_{p u, l}^{v}}^{1} \pi_{p u}(a) f(a) d a+\int_{a_{p r, l}^{v}}^{a_{p u, l}^{v}} \pi_{p r}(a) f(a) d a+\right. \\
& \left.+\int_{a_{\text {inf }}^{v}}^{a_{p r, l}^{v}} \pi_{p r}(a) f(a) d a\right]
\end{aligned}
$$

Proposition 1: Under regime $j(j=f, q, v)$, there exists a competitive equilibrium and it is unique. 
Before turning to the comparison of the regimes, it is worth summarizing some characteristics of the equilibria examined in this paper. First, all families whose children have the right to attend public universities or receive vouchers accept the benefits provided by the government. Second, some high income families do pay tuition to attend private university. The same is valid to low income families if they are not credit constrained. Otherwise, $a_{p u, l}^{j}=a_{p r, l}^{j}(j=f, q, v)$, that is, there is no private investment in education from low income families. Finally, one important implication from the equilibrium under the targeted voucher regime is the following:

Corollary 1: If $\pi_{p u}(a)<\pi_{p r}(a)$, then $a_{p u, l}^{v}=a_{p u, h}^{v}=1$.

The above corollary shows one obvious result: public university would not exist if a voucher system is introduced and the private university has a higher quality. ${ }^{18} \mathrm{~A}$ voucher's recipient would be able to choose a place either in the private or public university and would certainly opt to the former one. The non-recipients devoided from the free tuition alternative in the public universities would also choose the private alternative. This prospect suggests that a government policy based on a targeted voucher regime may suffer opposition from members of low quality public universities. ${ }^{19}$

\section{Efficiency Across Regimes}

This section compares the efficiency of the regimes: free tuition $(f)$, quotas $(q)$ and targeted voucher $(v)$. In order to perform this analysis, I use four different indicators: (i) the efficiency of public expenditures in education; (ii) the efficiency of the total, private and public, expenditures in education; (iii) the modulus of the difference in the threshold abilities behavior of both types of families; (iv) the quality of the labor force.

Before comparing the regimes, it is important to define formally all indicators. ${ }^{20}$ The first indicator is the efficiency of the public expenditures in education. It is measured by the ratio of the number (measure) of students who have their university education financed by the government and turn out to be individuals with a high level of human capital to the public expenditures in education. Obviously, a greater ratio indicates more efficient public investments as it is desirable to have more qualified indiviuals per amount spent. Formally, this indicator is equal to:

18 When $\pi_{p u}(a)=\pi_{p r}(a)$, families are indifferent from sending their children to private or public universities. In this case, it is not clear if public universities would coexist with private ones.

19 For a further discussion on the effects of the targeted voucher system, see Andrade (2009).

20 Caucutt and Kumar (2003) and Andrade (2004) use similar indicators. 


$$
E F F_{p u}^{j}=\frac{n_{h, 0}^{*}\left[\int_{a_{p u, h}^{1}}{ }^{j} \pi_{p u}(a) f(a) d a\right]+n_{i_{, 0}}\left[\int_{a_{p u, l}{ }^{j}} \pi_{p u}(a) f(a) d a\right]}{v E}
$$

and,

$$
\begin{aligned}
& E F F_{p u}^{v}=\frac{(1-I) n_{l, 0} \cdot\left[\int_{a_{p u, l}^{f}}^{a_{\text {sup }}^{v}} \pi_{p u}(a) f(a) d a+\int_{a_{\text {inf }}^{v}}^{a_{p u, l}^{f}} \pi_{p r}(a) f(a) d a\right]}{v E}+ \\
& +\frac{I n_{l, 0}^{*} \int_{a_{\text {inf }}^{v}}^{a_{\text {gup }}^{v}} \pi_{p r}(a) f(a) d a}{v E}
\end{aligned}
$$

respectively, for $j(j=f, q)$ and for the targeted vouchers system. In the expression for $E F F_{p u}^{v}, I$ is an indicator function that can assume two values: 0 if the low income families are credit constrained and the public universities' quality is at least as good as the private ones; and 1 otherwise. In the first case, some of the vouchers' recipients have the right to attend the public university and make this option. These are the students coming from low income families who also have the right to attend the public university under the free tuition regime. The others have only the private alternative. In the second case, the beneficiaries use the vouchers to attend private universities because either they are not qualified to attend the public universities or the private universities are better.

The second indicator is the efficiency of total expenditures in education. It is measured by the ratio of the number (measure) of students who turn out to be individuals with a high level of human capital to the total (private plus public) expenditures in education. Obviously, for the same reason as in the previous indicator, a greater ratio indicates more efficient investments. Formally, this indicator is equal to $(j=f, q, v)$ :

$$
E F F_{t o}^{j}=\frac{n_{h, 1}^{j}}{\left(v+n_{h, 0}^{*} \int_{a_{p r, h}^{j}}^{a_{p u, h}^{j}} f(a) d a+n_{l, 0}^{*} \int_{a_{p r, l}^{j}}^{a_{p u, l}^{j}} f(a) d a\right) E^{j}},
$$

The third indicator captures which system is more capable of allocating the best talents, individuals with the greatest abilities, to attend university, independently of their family's income's background. It can be seen as a measure of social mobility. Hence, it is interesting to compare the ability of the least able individual with a high income family background who attends university with the 
correspondent one from the low income family. Formally, this indicator denoted by $D I F$ is the difference of these abilities. For regime $j(j=f, q)$, the indicator is equal to $D I F^{j}=\left(a_{p r, l}^{j}-a_{p r, h}^{j}\right)$. For the voucher regime, the indicator is equal to $D I F^{j}=\left(a_{\mathrm{inf}}^{v}-a_{p r, h}^{v}\right)$.

Finally, the fourth and last indicator is the quality of the labor force at time $t=1$ measured by the fraction of individuals with high level of human capital $\left(n_{h, 1}^{j}, j=f, q, v\right)$.

I now turn to the results of the comparison of the regimes in terms of efficiency.

Proposition 2: $D I F^{v}<D I F^{j}$ and $n_{h, 1}^{v}>n_{h, 1}^{j}(j=f, q)$.

Proposition 3: There is a positive number of targeted vouchers such that $E F F_{t o}^{v}>E F F_{t o}^{j}(j=f, q)$.

The two above propositions show that the targeted voucher system is the most efficient in three out of the four indicators analyzed. It produces a greater quality of the labor force $(n)$, more social mobility $(D I F)$, and a better allocation of the total resources spent in higher education $\left(E E F_{t o}\right)$.

The intuition behind these results is the following. With vouchers, public resources are not wasted in providing higher education to individuals who have enough resources on their own and would use them to pay the full tuition if the free option is not available. This waste occurs either in the free tuition or the quota system.

Thus, under the targeted voucher system, limited resources are directed to those individuals who really need financial support to attend an university. Its implications are the following. On the one hand, it reduces the relationship between the student's family income and his capability of attending an university. That is, it increases social mobility.

On the other hand, the direct effect of vouchers is to decrease the skill premium, as it augments the ability range of those individuals coming from low income who attend university. At the margin, high income families become less inclined to send their children to university, which tends to reduce the effect on the skill premium. The net effect is a skill premium under the targeted vouchers system lower than the ones obtained in the free tuition and quotas regimes, which indicates a greater quality of the labor force.

Finally, there is a positive number of targeted vouchers that can make total investments in higher education more efficient under the targeted vouchers regime 
than the others. There is a positive number of vouchers that can be distributed to low income families such that in equilibrium: (i) the number of new university students coming from low income families are exactly equal to the number of students coming from high income families whose families decide not to send their children to university anymore (due to the lower skill premium), and (ii) the new students (from low income families) have a higher quality than the ones who do not attend university anymore (from high income families). The first feature guarantees that the same number of students attend university with the vouchers system in comparison with the others regimes. The second feature indicates that the average ability of the students attending university under vouchers is necessarily greater. Therefore, it is straighforward to show that the overall allocation of resources in higher education is more efficient under the vouchers regime. That is, $E F F_{t o}^{v}>E F F_{t o}^{j}(j=f, q)$.

Proposition 4: If $\pi_{p u}(a) \pi_{p r}(a)$, then $E F F_{p u}^{v}>E F F_{p u}^{j}(j=f, q)$ and if $\pi_{p u}(a)<\pi_{p r}(a)$, then $E F F_{p u}^{v}$ may be greater, equal or lower than $E F F_{p u}^{j}(j=f, q)$.

The above proposition indicates that the efficiency of the public investments in higher education under the targeted vouchers system is lower, in general, than in the other regimes. This is an expected result. As pointed out above, vouchers are directed to those individuals who really need financial support to attend an university. These students are in general the ones with a lower level of ability.

However, if the quality of the private university is greater, the result can be reversed. The reason is the following. When vouchers are introduced, its beneficiaries have, on average, a lower level of ability in comparison with students with the highest abilities who opt for the public universities because it is free of charge under the quota and free tuition regimes. However, as they opt for the private universities which are better, the overall investments in education by the government can actually increase.

It is interesting to note the following. In comparison with other regimes, vouchers produce, in general, a less efficient public investiments in higher education and a more efficient total (private and public) investments in education. Obviously, the efficiency of the whole educationl sector is the more relevant variable.

\section{Discussion}

The model used in this paper tries to capture the main features of the Brazilian higher education sector. Given the stylized nature of the model, it is interesting to 
discuss which hypothesis are crucial to reach the results and how robust they are if some changes in the structure of the model are introduced. It is not possible to intertwine this discussion with the lessons available from the empirical evidence on the use of vouchers in the higher education sector. The reason is that, to my knowledge, there is no country that had adopted such system in the higher education sector. When appropriate, though, it is interesting to pinpoint lessons learned from the most notorious and studied voucher program in the world, the Chilean nationalwide school choice system, in order to prevent mistakes when introducing a targeted voucher in the higher education sector. ${ }^{21}$

First, there is one important implicit assumption in the model: public universities do not operate under a " soft budget constraint". It means that, in order to survive, they have to be efficient and attract students. Otherwise, if they lose students to private universities because they are not free-tuition institutions anymore and are relatively less efficient, they end up stop operating and have to close its doors. In other words, when faced with this reality, the government would not provide extra funds and direct subsidies to the public universities to avoid its shut down. This assumption is important because it generates the necessary competition between private and public universities in the direction to an overall increase in the quality of the higher education institutions as only the most efficient ones are selected by the students. Hence, the possible existence of " soft budget constraints" for public universities is likely to mitigate the effects of the targeted voucher system in the increase in the quality of the labor or in the overall efficiency of the total investments in higher education. In contrast, the possible existence of a " soft budget constraint" for the public universities is unlikely to affect the result that the targeted voucher system would lead to an increase in social mobility, as the resources would still be directed to the students coming from low income families.

In fact, there is one important lesson from the Chilean experience: the existence of " soft budget constraints" did not provide the correct incentive for the public schools. In practice, there was no competition among private and public schools. The reason is that public schools faced " soft budget constraints" and did not stop operating and closed its doors even if they lost students. Hence, the system was not propered designed and it should not come as a surprise the fact that it did not lead to the expected results in terms of increasing the education quality as discus-

21 Obviously there are important differences between the higher education and the school sectors. In particular, the fact that it is mandatory for students to attend school whereas it is not for an university. For a further discussion on this issue, see Friedman (1962). The comparions have to be made with cautious. 
sed above. Such mistake should be avoided when introducing the targeted voucher system in the Brazilian higher education sector. ${ }^{22}$

Second, there is one implicit assumption that, under the targeted voucher system a private university, when faced with excess demand, would select the best students available from the candidates. The model explicitly assumes the same for the public universities. These features of the model recognize the fact that a customer-input technology is employed in the higher education sector. The highest the quality of incoming students (and customers), ceteris paribus, the greatest is the quality of outgoing students or the quality of educational services provided by the institution. In great lenght, it occurs because students benefit from the interaction with others, the so called peer-effect. ${ }^{23}$ In recognizing the importance of students' quality in the production of educational services, an university impose a very selective process to choose the students and restrict the supply. Even if one considers the peer-effect, the results in our model is unlikely to suffer any change because in both systems, in the current system and in the proposed targeted voucher system, a meritocratic system prevails and the relatively best students are grouped in the relatively best universities. In other words, the new system does not change a characteristic of the current one. ${ }^{24}$

Third, the model does not include two features discussed in the literature that analyzes the effects of affirmative action policies. One the one hand, students could benefit from the presence of individuals from different races, ethnicities, and income's family backgrounds on universities campuses. An environment characterized by diversity, which allows the exchange of different experiences of life among students, could have important impacts on the students' learning experiences, including a reduction in discrimination over time. One the other hand, quotas can make less rare the presence of role models from different races, ethnicities and income's family backgrounds. These individuals who are well successful in their careers, could serve as " examples" to younger individuals from less favorable groups in society, signalling to them that they can also succeed in their lives, and serving as

22 For a review of the Chilean experience, see Gallego and Hernando (2008) and McEwan et. al (2008).

23 There are mixed evidence on the recent work on peer effects in higher education. Sacerdote (2001) and Zimmerman (2003) find evidence of peer-effect among roomates. Arcidiano and Nicholson (2005) find no peer effect among medical students, while Dale and Krueger (1998) find mixed results.

24 The evidence on the Chilean voucher system registered a flow of the best public school students to private schools, a phenomenon called stratification, and a greater disparity in the quality of public schools vis-à-vis the private ones. When faced with excess of demand, private schools selected the best students because they are easier to teach, the costs to provide education to them are lower and the voucher value was the same for all students. In our model, the stratification would not change. The same phenomenon did not occur in the voucher system in Sweeden as the schools had little room to decide the rules to select its students - see Sandstrom and Bergstrom (2005). 
an incentive for them to pursue their objectives. However, the empirical evidence in the United States, the country that has adopted more aggressively affirmative action policies, does not indicate that these factors (the diversity and the " role model" factors) can impact in a significant way the educational quality of higher education and for this reason it was not incorporated in the model. ${ }^{25}$

Finally, the model assumes that two workers, one who attend a private university and the another a public university, as long as they obtain a high level of human capital, are perfect substitutes in the production function. This hypothesis obviously simplifies the problem as it limits the heterogeneity to two levels of human capital. This feature of the model does not play any important role in the results. Even if they are complementary inputs in the production function, the introduction of the targeted voucher system would increase the social mobility, as the resources are now directed to the low income families, and the quality of the labor force (and the efficiency of the overall investments in education) as, at the margin, more individuals would be able to attend an university.

\section{Conclusion}

The Brazilian higher education sector is clearly inefficient. On the one hand, it is clearly regressive and does not promote equality of opportunities. On the other hand, it is also inefficient as it does use the available resources in way to maximize the quality of the labor force.

This paper indicates that there is another system that can correct some of the inadequacies of the current one: targeted vouchers system. It leads to a higher quality of the labor force, more efficient allocation of resources and a greater social mobility. These are possibly just the initial effects of its introduction. The competition between private and public universities should cause additional desirable effects in the long run, mainly in terms of efficiency and greater quality of the universities.

Other countries also have a higher education sector with the same undesirable features of the Brazilian one, such as Argentina, Mexico and Spain. For example, public universities in Argentina and Mexico are tuition-free. In Spain, almost 80\% of the Spanish public universities funds come from the government. In Argentina, almost $50 \%$ of the public university students belong to the top $20 \%$ of the income distribution. In Spain, studies indicate that there is an important relationship be-

25 See Holzer and Neumark (2000) for the review of the literature on these and other aspects of the effects of affirmative action policies. 
tween an individual's family income and his ability to obtain an university degree. ${ }^{26}$ Despite having a higher education sector with its own characteristics, in light of the theoretical results for the Brazilian case, these countries should consider changing their systems by charging full tuition to those students who can pay. With these changes, private universities may emerge and increase the competition in the sector with positive effects on the quality of the labor force and the social mobility. The introduction of a targeted vouchers system may be a desirable step.

Finally, as voucher allows its beneficiaries to select which university to attend, one consequence of its introduction is the shut down of the less competitive public universities. In addition, some specific groups have their welfare reduced with vouchers in comparison with the current system. It occurs either because the skill premium is lower (due to the higher quality of the labor force) or they lose their right to attend the tuition free public universities. These two effects combined can explain possible oposition to the replacement of the current system by the the more efficient targeted vouchers one.

\section{References}

ALBRECHT, D.; ZIDERMAN, A. Funding mechanisms for higher education. World Bank Discussion Papers, 153, 1992.

ARCIDIACONO, P.; NICHOLSON, S. Peer effects in medical schools. Journal of Public Economics, 89, p.327-350, 2004.

ANDRADE, E. Growth, distribution, and school policy. 1998. (Doctoral Dissertation) - University of Chicago.

. Quotas in Brazilian public universities: good or bad idea? Revista Brasileira de Economia, out./dez. 2004.

.Targeted vouchers and its effects. 2009. (Mimeo).

; MOITA, R.; SILVA, C. Peer effect and competition in higher education. 2009. (Mimeo).

CAUCUTT, E.; KUMAR, K. Higher education subsidies and heterogeneity: a dynamic analysis. Journal of Economic Dynamic \& Control, 27, p. 1459-1502, 2003.

CHEN, Z.; WEST, E. Selective versus universal vouchers: modeling median voter preferences in education. American Economic Review, v. 90, n. 5, 2000.

CUNHA, F.; HECKMAN, J.; LOCHNER, L. ; MASTEROV, D. Interpreting the evidence on life cycle skill formation. NBER Working Paper, 11331, 2006.

26 For informations about the higher education systems in Argentina, Mexico and Spain see, respectively, Rozada and Menendez (2000), Malledo and San Segundo (2000) and Lopez-Acevedo and Salinas (2000). 
CUNHA, F.; HECKMAN, J. The economics and psychology of inequality and human development. NBER Working Paper, 14695, 2009.

DALE, S.; KRUEGER, A. Estimating the payoff to attending a more selective college: an application of selection on observables and unobservables. NBER Working Paper, 7322, 1998.

FRIEDMAN, M. Capitalism and freedom. Chicago University Press, 1962.

GALLEGO, F.; HERNANDO, A. On the determinants and implications of school choice: semi-structural simulations for Chile. Economia; Fall, 2008.

HOLZER, H.; NEUMARK, D. Assessing affirmative action. Journal of Economic Literature, September, v. 38, iss. 3, 2000.

LADD, H. School vouchers: a critical view. Journal of Economic Perspectives, v. 16, n. 4, Fall, 2002.

LOPEZ-ACEVEDO, G.; SALINAS, A. The distribution of Mexico's public spending on education. Policy Research Working Paper 2404, The World Bank, 2000.

MALLEDO, J.; SAN SEGUNDO, M. La financiación de la enseñanza superior: un análisis comparado de la situación española. Papeles de Economia Española, n. 86, 2000.

McEWAN, P.; URQUIOLA, M.; VEGAS, E. School choice, stratification, and information on school performance: lessons from Chile. Economia, Spring, 2008.

NEAL, D. How vouchers could change the market for education. Journal of Economic Perspectives, v. 16, n. 4, Fall, 2002.

ROZADA, M.; MENENDEZ, A. Public university in Argentina: subsidizing the rich? 2000. (Mimeo).

SACERDOTE, B. Peer effects with random assignment: results from Darthmouth Roomates. Quarterly Journal of Economics, 116, p. 681-704, 2001.

SANDSTROM, F.; BERGSTROM, F. School vouchers in practice: competition will not hurt you. Journal of Public Economics, 89, 2005.

STOKEY, N. Free trade, factor returns, and factor accumulation. Journal of Economic Growth, v. 1, iss. 4, p. 421-447, December 1996.

VELOSO, F.; FERREIRA, S. A reforma da educação. In: PINHEIRO, A.; GIAMBIAGI, F. (Org.). Rompendo o marasmo - a retomada do desenvolvimento no Brasil. Editora Campus, 2006.

ZIMMERMAN, D. Peer effects in academic outcomes: evidence from a natural experiment. The Review of Economics and Statistics, v. 85, n. 1, p. 9-23, 2003. 


\section{Appendix A}

Proposition 1: Under regime $j(j=f, q, v)$, there exists a competitive equilibrium and it is unique.

Proof. Under regime $j$, the equilibrium is characterized by five unknows $\left(n_{i, 1}^{j}, w_{i, 0}^{j}, w_{i, 1}^{j}\right.$, $a_{p u, i}^{j}$ and $a_{p r, i}^{j}$ ) and five equations (two first-order conditions of the firm's problem, the law of motion for the variable $n_{h, 1}$ and the solutions to both types of individuals' problem). ${ }^{27}$

Let's first examine the quota regime. Departing from the situation in which there is only public investment in education and using assumptions 2 e 3 , one finds that:

$$
\beta \pi_{p r}\left(a_{p u, l}^{q}\right)\left[u\left(w_{h, 1}^{\prime}\right)-u\left(w_{l, 1}^{\prime}\right)\right]>u\left((1-\tau) w_{i, 0}\right)-u\left((1-\tau) w_{i, 0}-E\right)=A_{i} .
$$

In above equation, the RHS is constant. As the $L H S$ is greater than the $R H S$, individuals from high income family will invest in private education. The same occurs with individuals from low income families if $(1-\tau) w_{l, 0}>E$. As a consequence, $\mathrm{n}_{h, 1}$ and $w_{l, 1}$ increase, and $w_{h, 1}$ decreases. All these changes lead to a reduction in the $L H S$. As $\pi_{p r}(0)=0$, there is one and only one fraction of individuals with high level of human capital (and then unique wages and threshold abilities) that equates the LHS and the RHS in the above equation.

The proof is similar to the regimes $f$ and $v$.

Corollary 1: If $\pi_{p u}(a)<\pi_{p r}(a)$, then $a_{p u, l}^{v}=a_{p u, h}^{v}=1$.

Proof. For any $a$ and $w_{h, 1}>w_{l, 1}$, the following inequality holds: (if $V 0, i=h, l$ )

$$
\begin{aligned}
& u\left((1-\tau) w_{i, 0}-E+V\right)+\beta\left[\pi_{p u}(a) u\left(w_{h, 1}\right)+\left(1-\pi_{p u}(a)\right) u\left(w_{l, 1}\right)\right] \\
& >u\left((1-\tau) w_{i, 0}-E+V\right)+\beta\left[\pi_{p r}(a) u\left(w_{h, 1}\right)+\left(1-\pi_{p r}(a)\right) u\left(w_{l, 1}\right)\right] .
\end{aligned}
$$

Then $a_{p u, l}^{v}=a_{p u, h}^{v}=1$.

Proposition 2: $D I F^{v}<D I F^{j}$ and $n_{h, 1}^{v}>n_{h, 1}^{j}(j=f, q)$.

Proof. This proposition is valid with $(1-\tau) w_{l, 0} £ E$ and $\pi_{p r}(a) £ \pi_{p u}(a)$. The proof is analogous in all possible cases. I show here the case in which low income families are not credit constrained $\left((1-\tau) w_{l, 0}>E\right)$ and public universities have a greater

27 Under regime v, $a_{\text {sup }}^{v}=a_{p r, l}^{v}$ and $a_{\text {inf }}^{v}$ is determined by $s=n_{l, 0}^{*} \int_{a_{\text {inf }}^{v}}^{a_{\text {sup }}^{v}} f(a) d a$. 
quality $\left(\pi_{p u}(a)>\pi_{p r}(a)\right)$, and compare the targeted vouchers regime with the free tutition one.

The following condition must hold in the competitive equilibrium under regime $j$ $(j=f, q, v)$ :

$\beta \pi_{p r}\left(a_{p r, i}^{j}\right)\left[u\left(w_{h, 1}\right)-u\left(w_{l, 1}\right)\right]=u\left((1-\tau) w_{i, 0}\right)-u\left((1-\tau) w_{i, 0}-E\right) \equiv A_{i}$.

I need to show that $a_{p r, i}^{v}<a_{p r, i}^{f}(i=h, l)$ and $a_{p r, l}^{f}>a_{\text {inf }}^{v}$. Suppose that $a_{p r, i}^{v}=a_{p r, i}^{f}$. Then:

$$
\begin{aligned}
& n_{h, 1}^{f}=n_{h, 0}^{*}\left[\int_{a_{p u, h}^{f}}^{1} \pi_{p u}(a) f(a) d a+\int_{a_{p r, h}^{f}, a_{p r, h}^{f}}^{f} \pi_{p r}(a) f(a) d a\right]+ \\
& +n_{l, 0}^{*}\left[\int_{a_{p u, l}^{f}}^{1} \pi_{p u}(a) f(a) d a+\int_{a_{p r, l}^{f}}^{a_{p u, l}^{f}} \pi_{p r}(a) f(a) d a\right]<n_{h, 1}^{\prime}= \\
& =n_{h, 0}^{*}\left[\int_{a_{p u, h}^{f}}^{1} \pi_{p u}(a) f(a) d a+\int_{a_{p r, h}^{f}}^{a_{p u, h}^{f}} \pi_{p r}(a) f(a) d a\right]+ \\
& +n_{l, 0}^{*}\left[\int_{a_{p u, l}^{f}}^{1} \pi_{p u}(a) f(a) d a+\int_{a_{p r, l}^{f}}^{a_{p u, l}^{f}} \pi_{p r}(a) f(a) d a\right. \\
& \left.+\int_{a_{\mathrm{inf}}^{v}}^{a_{p r, l}^{f}} \pi_{p r}(a) f(a) d a\right],
\end{aligned}
$$

where $s=n_{l, 0}^{*} \int_{a_{\text {inf }}^{v}}^{a_{p r, l}^{f}} f(a) d a$, and $n_{h, 1}^{\prime}$, the fraction of individuals with high level of human capital at $t=1$ when $a_{p r, i}^{v}=a_{p r, i}^{f}$ and with targeted vouchers, is greater than $n_{h, 1}^{f}$, as the vouchers' recipients are now attending university. As $n_{h, 1}^{\prime}>n_{h, 1}^{f}$, then $w_{h, 1}^{f}>w_{h, 1}^{\prime}$ and $w_{l, 1}^{f}<w_{l, 1}^{\prime}$, where $w_{i, 1}^{\prime}$ is the wage of individual type $i$ at $t=1$ when $a_{p r, i}^{f}=a_{p r, i}^{v}$ and with targeted vouchers. It means that the skill premium is lower. Hence, the combination $a_{p r, i}^{f}=a_{p r, i}^{v}$ and $w_{h, i}^{v}=w_{h, i}^{\prime}$ do not satisfy equation (4) that must hold in the competitive equilibrium under regime $v$ :

$$
\beta \pi_{p r}\left(a_{p r, i}^{f}\right)\left[u\left(w_{h, 1}^{\prime}\right)-u\left(w_{l, 1}^{\prime}\right)\right]<A_{i} .
$$

Hence, $a_{p r, i}^{f}=a_{p r, i}^{v}$ and $w_{i, 1}^{\prime}$ are not part of the competitive equilibrium under the targeted vouchers regime. To restore equality, the LHS must be greater, that is, the ability of those individuals coming from high and low income families must be greater, which increases the skill premium (without returning to the previous 
level, though). Therefore, $a_{p r, i}^{v}>a_{p r, i}^{f}, n_{h, 1}^{v}>n_{h, 1}^{f}$ and $a_{p r, l}^{f}>a_{\mathrm{inf}}^{v}$. As $a_{p r, h}^{v}>a_{p r, l}^{f}$ and $a_{p r, l}^{f}>a_{\mathrm{inf}}^{v}$, then $D I F^{v}<D I F^{f}$.

Proposition 3: There is a positive number of targeted vouchers such that $E F F_{\text {to }}^{v}>E F F_{\text {to }}^{j}(j=f, q)$.

Proof. This proposition is valid with $(1-\tau) w_{l, 0} £ E$ and $\pi_{p r}(a) £ \pi_{p u}(a)$. The proof is analogous in all possible cases. I show here the case in which low income families are not credit constrained $\left((1-\tau) w_{l, 0}>E\right)$ and public universities have a greater quality $\left(\pi_{p u}(a)>\pi_{p r}(a)\right)$, and compare the targeted vouchers regime with the free tutition one.

There is a positive number of vouchers that can be distributed to low income families such that in the equilibrium: (i) the number of new university students coming from low income families are exactly equal to the number of students coming from high income families whose families decide not to send their children to university anymore (due to the lower skill premium), and (ii) the new students (from low income families) have a higher quality than the ones who do not attend university anymore (from high income families). Due to (i),

$$
\begin{aligned}
& \left(s+n_{h, 0}^{*} \int_{a_{p r, h}^{v}}^{1} f(a) d a+n_{l, 0}^{*} \int_{a_{p r, l}^{v}}^{1} f(a) d a\right) E \\
& =\left(s+n_{h, 0}^{*} \int_{a_{p r, h}^{f}}^{a_{p u, h}^{f}} f(a) d a+n_{l, 0}^{*} \int_{a_{p r, l}^{f}}^{a_{p u, l}^{f}} f(a) d a\right) E
\end{aligned}
$$

and due to (ii), $n_{h, 1}^{v}>n_{h, 1}^{f}$. Therefore, $E F F_{t o}^{v}>E F F_{t o}^{f}$.

Proposition 4: If $\pi_{p u}(a) \pi_{p r}(a)$, then $E F F_{p u}^{v}>E F F_{p u}^{j}(j=f, q)$ and if $\pi_{p u}(a)<\pi_{p r}(a)$, then $E F F_{p u}^{v}$ may be greater, equal or lower than $E F F_{p u}^{j}(j=f, q)$.

Proof. Let's first consider the case in which $\pi_{p u}(a) \pi_{p r}(a)$. Under this condition, $n_{h, 0}^{*}\left[\int_{a_{p u, h}^{j}}^{1} \pi_{p u}(a) f(a) d a\right]+n_{l, 0}^{*}\left[\int_{a_{p u, l}^{j}}^{1} \pi_{p u}(a) f(a) d a\right]$ is always greater than:

$$
\begin{aligned}
& (1-I) n_{l, 0}^{*}\left[\int_{a_{p u, l}^{f}}^{a_{\text {sup }}^{v}} \pi_{p u}(a) f(a) d a+\int_{a_{\text {inf }}^{v}}^{a_{p u, l}^{f}} \pi_{p r}(a) f(a) d a\right] \\
& +I n_{l, 0}^{*} \int_{a_{\text {inf }}^{v}}^{a_{\text {sup }}^{v}} \pi_{p r}(a) f(a) d a,
\end{aligned}
$$


$I=0,1, j=f, q$. Hence, $E F F_{p u}^{v}<E F F_{p u}^{j}$. However, when $\pi_{p u}(a)<\pi_{p r}(a)$, $E F F_{p u}^{v} \square E F F_{p u}^{j}$ if

$$
\begin{aligned}
& n_{l, 0}^{*} \int_{a_{\text {inf }}^{v}}^{a_{\text {sup }}^{v}} \pi_{p r}(a) f(a) d a \\
& \mathrm{v} n_{h, 0}^{*}\left[\int_{a_{p u, h}^{j}}^{1} \pi_{p u}(a) f(a) d a\right]+n_{l, 0}^{*}\left[\int_{a_{p u, l}^{j}}^{1} \pi_{p u}(a) f(a) d a\right],
\end{aligned}
$$

$(j=f, q)$. 